\title{
Hubungan Pola Asuh Orang Tua dengan Perkembangan Kognitif Anak Kelas 1 di Sekolah Dasar Negeri Bung Makassar
}

\author{
Erna Kadrianti ${ }^{1 *}$, Pajeriaty $^{2}$ \\ 1*. STIKES Nani Hasanuddin Makassar, Jl. P. Kemerdekaan VIII No.24, Kota Makassar, Indonesia, 90245 \\ 2. STIKES Nani Hasanuddin Makassar, Jl. P. Kemerdekaan VIII No.24, Kota Makassar, Indonesia, 90245 \\ *e-mail :ekadrianti@stikesnh.ac.id
}

\begin{abstract}
Parenting style is a way of parents in helping children's ability to think to be better. Parents have their own way to nurture and educate children. The aim of this study is to find out the correlation of parenting style and cognitive growth on grade I children in Bung Makassar Elementary School. The method used is a non-experimental type with cross sectional design and total sampling technique as the sampling method. Population in this study are 32 respondents from grade I children in Bung Makassar Elementary School. The result shows authoritarian parenting style with high cognitive growth on children are 5 respondents (29.4\%), 12 respondents (70.6\%) of authoritarian parenting style with high cognitive growth on children, 6 respondents $(66.7 \%)$ of permissive parenting style with low cognitive growth on children, 3 respondents (33.3\%) of permissive parenting style with low cognitive growth on children, while for the democratic parenting style are 0 respondents (0.0\%) with high cognitive growth on children and 6 respondents (100\%) with low cognitive growth on children. Based on the Chi-Square test from 32 respondents, the value of $p=0.024<$ $\alpha=0.05$, therefore the $H 0$ is rejected while the $H$ is accepted which means there are correlations between parenting style and cognitive growth on grade I children in Bung Makassar Elementary School. The conclusion from this study, parenting style is very important for children cognitive. This shows that every parent has different style of parenting children. It can be conclude that parenting style is correlated to cognitive growth on children.It is hope for the parents to increase their knowledge about the basic parenting style and cognitive growth on children.
\end{abstract}

Keywords: Cognitive growth on children, parenting style

\begin{abstract}
Abstrak
Pola asuh orang tua adalah suatu cara yang ditempuh oang tua dalam membantu kemampuan berfikir anak untuk lebih baik. Orang tua memiliki cara sendiri dalam mengasuh anak dan mendidik anak. Tujuan dalam penelitian ini untuk mengetahui hubungan pola asuh orang tua dengan perkembangan kognitif anak kelas I di Sekolah Dasar Negeri Bung Makassar. Metode dalam penelitian ini adalah jenis penelitian non eksperimen dengan rancangan cross sectional dengan tehnik sampling menggunakan teknik total samplling. Sampel dalam penelitian ini di Sekolah Dasar Negeri Bung Makassar semua anggota populasi menjadi sampel sebanyak 32 responden. Hasil penelitian didapatkan pola asuh orang yang otoriter dengan perkembangan kognitif anak yang tinggi berjumlah 5 responden $(29,4 \%)$ pola asuh orang tua yang otoriter dengan perkembangan kognitif anak yang tinggi berjumlah 12 responden (70,6\%).pola asuh orang tua yang permisif dengan perkembangn kognitif anak yang rendah berjumlah 6 responden $(66,7 \%)$, dan pola asuh orang tua yang permisif dengan perkembangan kognitif anak yang tinggi beejumlah 3 responden (33,3\%). Pola asuh orang tua yang demokratis dengan perkembangan kognitif anak yang rendah berjumlah 0 responden $(0,0 \%)$ dan pola asuh orang tua demokratis dengan perkembangan kognitif anak yang tinggi berjumlah 6 responden (100\%). Berdasarkan dari 32 responden dengan hasil menggunakan uji Chi-Square didapatkan nilai $\rho=0,024<\alpha=0,05$ maka H0 ditolak dan Ha diterima artinya ada hubungan antara pola asuh orang tua dengan perkembangan kognitif anak kelas I di Sekolah Dasar Negeri Bung Makassar. Kesimpulan dalam penelitian ini pola asuh orang tua sangat berperan penting bagi kognitif anak. Hal ini menunjukan bahwa setiap orang tua memiliki pola asuh yang berbeda-beda dalam mengasuh anaknya. Maka dapat di simpulkan bahwa terdapat Hubungan antara Pola Asuh Orang Tua dengan Perkembangan Kognitif Anak. Harapan Untuk menambah wawasan dan pengetahuan orang tua dalam mengenal dasar-dasar pola asuh orang tua dengan perkembangan kognitif anak.
\end{abstract}

Kata kunci: Pola asuh orang tua, perkembangan kognitif anak 


\section{Pendahuluan}

Perkembangan kognitif anak berhubungan dengan kemampuan otak, sehingga berkaitan erat dengan tingkat kecerdasan atau intelegensi seseorang anak. Fungsi kognitif memungkinkan seseorang untuk berfikir, mengingat, menganalisis, belajar, dan secara umum melakukan aktifitas mental yang lebih tinggi (higher mental processes) (Shantika, 2017)

Perkembangan anak adalah semua aspek perkembangan individu, antara lain fisik, kognitif, emosi, sosial, moral, dan minat. Perlu diperhatikan dan dikembangkan karena semuanya penting dan saling mempengaruhi. Hambatan yang terjadi pada salah satu aspek selain akan menghambat perkembangan aspek lain. Misalnya keterbatasan kemampuan kognitif pada anak-anak yang mengalami keterbelakangan mental akan mengakibatkan hambatan pada keterampilan bicara, gangguan emosi. Dan hambatan yang menyesuai diri. Sebaliknya pada anak yang tidak ada hambatan fungsi otaknya. Maka kemampuan kognitifnya dapat berkembangan dengan baik, memiliki kemampuan memecahkan masalah, dan menyesuaikan diri yang baik (Cristiana, 2014)

Perkembangan menuju pada bertambahnya fungsi tubuh yang lebih kompleks pada pola struktur dan dapat diramal sebagai hasil proses pematangan dan belajar. Dalam perkembangan anak sangat memerlukan perhatian, kasi sayang, sentuhan, dan kesungguhan dalam pengasuhan dari orang tua serta orang dewasa disekitarnya. Sikap dan perilaku orang tua atau pengasuh yang disebut diatas. Merupakan salah satu syarat bagi perkembangan secara optimal aspek-aspek didalam diri anak (Susanto, 2014)

Pola asuh adalah suatu cara terbaik yang dapat ditempuh orang tua dalam mendidik anak sebagai perwujudan dan rasa tanggung jawab kepada anak. Tetapi ahli lain memberikan padangan lain, seperti Sam Vaknin (2009) mengutarakan bahwa pola asuh sebagai "parenting is interaction between parent's and children during their care". Dari pengertian diatas dapat disimpulkan bahwa. Pola asuh orang tua adalah suatu keseluruhan interaksi orang tua dan anak., dimana orang tua yang memberikan dorongan bagi anak dengan mengubah tingkah laku, pengetahuan, dan nilai-nilai yang dianggap penting bagi orang tua agar anak bisa mandiri, tumbuh serta berkembang secara sehat dan optimal, memiliki rasa percaya diri, memiliki sifat rasa ingin tahu, bersahabat, berorientasi untuk sukses (Tridhonanto, 2014)

Orang tua mempunyai peran yang sangat penting agar anak memiliki teman dalam rangka membatu perkembangan sosialnya. Anak tidak dilahirkan dengan keterampilan sosial. Anak membutuhkan orang tua yang berperan aktif untuk mebantunya mempersiapkan diri berinteraksi dengan orang lain/teman sebayanya dengan cara membina hubungan yang baik dengan anak, yaitu hubungan yang didasari kasi sayang., penerimaan, hangat, dan respectful. Orang tua juga dapat menjadi model yang baik bagi anak karena akan melihat dan mencontoh bagaimana orang tuanya berinteraksi dengan dirinya dan orang lain (Cristiana, 2014)

Dari hasil penelitian Cendy Dwiayu, 2017 Hubungan Pola Asuh Orang Tua Dengan Perkembangan Kognitif Anak Usia 3-4 tahun di PAUD Kecamatan Manggelang Selatan. Dari hasil penelitian diketahui bahwa pola asuh orang tua yaitu pola asuh demokratis (53,3\%). Dan mayoritas perkembangan kognitif anak (83\%). Dengan hasil analisis menunjukan bahwa pola asuh orang tua sangat mempengaruhi tingkat perkembangan kongnitif anak. disimpulkan bahwa pola asuh demokratis menjadi lebih dominan yang dapat membentuk perkembangan anak untuk menjadi lebih baik.

Dari data yang didapatkan di Sekolah Dasar Negeri Bung Makassar di tahun 2018 dengan total murid secara keseluruhan berjumlah 196 siswa, terdiri dari 102 siswa perempuan dan 94 siswa laki-laki. Siswa kelas I berjumlah 32 orang, kelas II berjumlah 30 orang, kelas III berjumlah 33 orang, kelas IV berjumlah 33 orang, kelas V berjumlah 37 orang, dan kelas VI berjumlah 35 orang.

Berdasarkan wawancara dengan kepala sekolah bahwa siswa diusia ini. Siswa sering bermain dengan teman sebanyanya. siswa kurang memperhatikan belajarnya disekolah maupun dirumah. Kepala sekolah mengatakan bahwa model pembelajaran yang guru berikan hanya berfokus pada buku bisa membuat siswa bosan dan siswa kurang memperhatikan guru menjelaskan didepan, siswa membutuhkan bahasa yang bisa dimengerti dan hubungan sosial yang lebih luas. Mengenal jati dirinya, dan mendorong anak menjadi berani dan menimbulkan rasa percaya diri. Kepala sekolah juga memberikan tugas tambahan kepada guru-guru untuk membina siswa dalam mengikuti banyak lombalomba, agar mental siswa terbangun dalam mengikuti lomba tersebut.

Dengan melihat data diatas maka peneliti tertarik untuk mengetahui Hubungan Pola Asuh Orang Tua dengan Perkembangan Kognitif Anak Kelas I Di Sekolah Dasar Negeri Bung Makassar.

\section{Metode}

Penelitian ini adalah jenis penelitian non eksperimen dengan rancangan cross sectional. Populasi dalam penelitian ini adalah keseluruhan dari kelas I di sekolah dasar Bung Makassar. sampel menggunakan Teknik Sampling nonprobability sampling dengan teknik total sampling cara pengambilan sampel dengan mengambil semua anggota populasi menjadi sampel sebanyak 32 responden 
1. Kriteria Inklusi

a. Ibu yang memiliki anak di Sekolah Dasar Negeri Bung Makassar.

b. Ibu yang anaknya berada dikelas I

c. Ibu yang bersedia menjadi responden

2. Kriteria Eksklusi
a. Ibu yang pada saat penelitian berlangsung tidak berada di lokasi penelitian
b. Ibu yang anaknya di kelas II dan VI.
c. Ibu dalam kondisi tidak sehat

Pengumpulan data menggunakan :

1. Data primer

Dikumpukan oleh peneliti langsung dari sumber data atau responden (Sudibyo Supardi dan Rustika, 2013).

2. Data Sekunder

Data yang telah tersedia hasil pengumpulan data untuk keperluan tertentu, yang dapat digunakan sebagai atau seluruhnya sebagai data sumber data penelitian (Sudibyo Supardi, dan Rustika, 2013).

Pengelolaan Data

1. Editing

2. Coding

Editing dalah upaya untuk memeriksa kembali kebenaran data yang diperoleh atau dikumpulkan. kategorì

3. Entri data

Data entri adalah kegiatan memasukkan data yang telah dikumpulkan ke dalam master tabel atau database computer, kemudian membuat distribusi frekuensi sederhana atau biasa juga dengan membuat table kontigensi.

Analisis Data

1. Analisis Univariat

Analisis univariat adalah analisis yang digunakan pada sebuah variabel. Dalam suatu penelitian, baik yang diperoleh dari melalui obsevasi, wawancara, kuesioner maupun dokumentasi, analisis univariat dapat disajikan dalam bentuk distribusi frekuensi, tendensi sentral dan nilai sebar dari variabel.

2. Analisis Bivariat

Analisis bivariat adalah analisis yang dilakukan pada dua variabel. Jenis uji yang digunakan bisa berupa uji perbedaan hubungan besar resiko

\section{Hasil}

Tabel 1. Distribusi karakteristik responden menurut kelompok umur anak kelas 1 di sekolah sd negeri bung makassar

\begin{tabular}{ccc}
\hline Umur Anak & Frekuensi & Presentase (\%) \\
\hline $4-6$ & 22 & 68,8 \\
$7-11$ & 10 & 31,3 \\
\hline Total & 32 & 100,0 \\
\hline
\end{tabular}

Tabel.1 menjelaskan bahwa karakteristik responden berdasarkan kelompok umur anak tertinggi yaitu kelompok umur 4-6 tahun sebesar $68,8 \%$ dan terendah pada kelompok usia 7-11 tahun sebesar 31,3\%

Tabel 2. Distribusi karakteristik responden menurut kelompok umur responden di sekolah sd negeri bung makassar

\begin{tabular}{ccc}
\hline Umur Responden & Frekuensi & Presentase (\%) \\
\hline $17-25$ & 15 & 46,8 \\
$26-35$ & 17 & 53,1 \\
\hline Total & 32 & 100,0 \\
\hline
\end{tabular}

Tabel.2 menjelaskan bahwa karakteristik responden berdasarkan kelompok umur responden tertinggi yaitu kelompok umur 17-25 tahun sebesar 46,8\% dan terendah pada kelompok usia 26-35 tahun sebesar 53,1\% 
Tabel 3. Distribusi karakteristik responden menurut kelompok umur responden di sekolah sd negeri bung makassar

\begin{tabular}{ccc}
\hline Umur Responden & Frekuensi & Presentase (\%) \\
\hline $17-25$ & 15 & 46,8 \\
$26-35$ & 17 & 53,1 \\
\hline Total & 32 & 100,0 \\
\hline
\end{tabular}

Tabel. 3 menjelaskan bahwa karakteristik responden berdasarkan kelompok jenis kelamin yaitu sama antara laki-laki dan perempuan sebesar $50 \%$.

Tabel 4. Distribusi responden berdasarkan hubungan pola asuh orang tua dengan perkembangan kognitif anak kelas i di sekolah dasar negeri bung makassar

\begin{tabular}{ccccccc}
\hline \multirow{2}{*}{$\begin{array}{c}\text { Pola Asuh Orang } \\
\text { Tua }\end{array}$} & \multicolumn{3}{c}{ Perkembangan Kognitif Anak } & \multicolumn{2}{c}{ Total } \\
\cline { 2 - 7 } & $\mathbf{n}$ & $\mathbf{\%}$ & $\mathbf{n}$ & $\mathbf{\%}$ & $\mathbf{n}$ & $\mathbf{\%}$ \\
\hline Otoriter & 12 & 70,6 & 5 & 29,4 & 17 & 100 \\
Permisif & 3 & 33,3 & 6 & 66,7 & 9 & 100 \\
Demokratis & 6 & 100 & 0 & 0,0 & 6 & 100 \\
\hline Total & 22 & 65,6 & 11 & 34,4 & 32 & 100 \\
\hline \multicolumn{7}{c}{$p=0,024$} \\
\hline
\end{tabular}

Berdasarkan tabel diatas dari 32 responden (100\%), menunjukan bahwa pola asuh orang tua yang otoriter dengan perkembangan kognitif anak yang rendah sebanyak 5 responden $(29,4 \%)$ pola asuh orang tua yang otoriter dengan perkembangan kognitif anak yang tinggi sebanyak 12 responden (70,6\%). Dan pola asuh orang tua yang permisif dengan perkembangan kognitif anak yang rendah sebanyak 6 responden $(66,7 \%)$, pola asuh orang tua yang permisif dengan perkembangan kognitif anak yang tinggi berjumlah 3 responden (33,3\%). Sedangkan pola asuh orang tua yang demokratis dengan perkembangan kognitif anak yang rendah berjumlah 0 responden $(0,0 \%)$ pola asuh orang tua yang demokratis dengan perkembangan kognitif anak yang tinggi sebanyak 6 responden $(100,0 \%)$.

Berdasarkan Hasil analisa uji Chi-Square test maka didapatkan nilai p 0,024 di mana nilai $\alpha=0,05$. Karena nilai $\mathrm{p}$ $0,024<\alpha=0,05$. Maka dapat di simpulkan bahwa terdapat Hubungan antara Pola Asuh Orang Tua dengan Perkembangan Kognitif Anak

\section{Pembahasan}

Berdasarkan hasil pengelolahan data dari tabulasi silang yang sesuai dengan tujuan penelitian yaitu untuk mengetahui hubungan pola asuh orang tua dengan perkembangan kognitif anak kelas 1 di Sekolah Dasar Negeri Bung Makassar, maka pembahasan hasil penelitian ini diuraikan sebagai berikut:

Hubungan Pola Asuh Orang Tua dengan Perkembangan Kognitif Anak

Berdasarkan hasil uji Chi-Square test yang diperoleh dari nilai p $0,024<\alpha=0,05$ maka terdapat hubungan antara pola asuh orang tua dengan Perkembangan Kognitif Anak. Dari jumlah 32 responden yang memiliki pola asuh orang tua yang otoriter dengan perkembangan kognitif anak yang tinggi berjumlah 12 responden (70,6\%) hal ini menunjukan bahwa pola asuh orang tua dengan menerapkan peraturan, hukuman serta disiplin dengan baik kepada anak, maka anak akan menjadi anak yang cerdas dan menghormati orang tua. Sehingga perkembangan kognitif anak tinggi, dan pola asuh orang tua yang permisif dengan perkembangan kognitif anak yang rendah berjumlah 6 responden $(66,7 \%)$ hal ini disebabkan oleh orang tua yang tidak memberikan perhatian dan pengawasan kepada anaknya maka anak dapat melakukan apapun yang anak inginkan sehingga anak merasa bebas dan anak leluasa melakukan hal-hal yang negatif akibatnya perkembangan kognitif anak rendah. Sedangkan pola asuh orang tua yang demokratis dengan perkembangan kognitif anak yang tinggi berjumlah 6 responden (100\%) hal ini menunjukan bahwa pola asuh orang tua yang menunjukan sikap hangat kepada anak, bertanggung jawab dan mendukung minat dan bakat anak maka anak merasa percaya diri dan tumbuh serta berkembang secara optimal sehingga perkembangan kognitif anak tinggi.

Sesuai dengan teori (Shantika, 2017) mengatakan bahwa pola asuh orang tua diartikan sebagai sebuah orang tua dalam menjaga, merawat dan mengasuh anaknya. Anak berhak mendapatkan kasih sayang dan perhatian dari orang tuanya. Setiap orang tua memiliki cara yang berbeda-beda dalam mengasuh dan mendidik anaknya. Jika anaknya diajarkan dengan penuh kasih sayang, maka kelak anak juga memiliki sikap kasih sayang yang sama dimiliki orang tuanya. Dan sebaliknya, jika orang tua menggunakan cara kasar dan bahkan melakukan kekerasan fisik, maka 
perkembangan kognitif anak akan terganggu dan anak terbawah hingga ia dewasa. Perkembangan kognitif anak berhubungan dengan kemampuan otak. Berkaitan erat dengan tinggkat kecerdasan atau intelegensi seseorang anak. Fungsi kognitif seseorang untuk berfikir, mengingat, menganalisis, belajar dan aktivitas mental.

(Mutiara, 2015) berpendapat bahwa orang tua berperang penting bagi tumbuh kembang anak. anak merupakan kewajiban bagi setiap orag tua dalam usaha membentuk pribadi anak. dengan menjaga dan melindungi serta menanamkan rasa kasih sayang kepada anak-anaknya agar kelak anak tersebut dibekali dengan rasa sayang. Jika orang tua mengaalami kesulitan dalam proses mengasuh anaknya maka anak mengalami gangguan pada perkembangan kognitifnya. Orang tua yang terlalu lelah karena bekerja dan ingin anaknya diam, sopan dan tentang. Maka merugikan pertumbuhan anak sehingga anak-anak ini kehilangan kesempatan untuk mengembangkan kompotensi dibidang mereka dan berdampak pada masa-masa datang.

Hasil penelitian ini sejalan dengan penelitian (Kusuma \& Wadi, 2015) dengan judul: Pengaruh Pengasuhan Ibu dan Nenek Terhadap Perkembangan Kemandirian dan Kognitif Anak Usia Prasekolah. Dari hasil penelitian menunjukan $\mathrm{p}=0,01$ dengan nilai $\alpha=0,05$. Maka terdapat pengaruh yang signifikan antara Pengasuhan Ibu dan Nenek Terhadap Perkembangan Kemandirian dan Kognitif Anak.

Menurut asumsi peneliti, pola asuh orang tua sangat berperan penting bagi pertumbuhan kognitif anak. Setiap orang tua memiliki cara yang berbeda-beda dalam memgasuh anaknya. Pola asuh juga mempunyai hasil perkembangan kognitif dengan memberikan stimulasi yang sesuai. Jika perkembangan kognitif anak berjalan dengan baik, maka anak juga semakin baik dan memahami berbagai nilai moral dan agama. Orang tua merupakan faktor pendukung terpenting bagi anak dan selalu memberikan tanggung jawab penuh sehingga anak bisa tumbuh kreatif, cerdas dan memberikan kesempatan belajar, untuk mampu mandiri, memperoleh rasa aman dan berkembang secara optimal.

\section{Kesimpulan}

Pola asuh orang tua sangat berperan penting bagi kognitif anak. Hal ini menunjukan bahwa setiap orang tua memiliki pola asuh yang berbeda-beda dalam mengasuh anaknya. Maka dapat di simpulkan bahwa terdapat Hubungan antara Pola Asuh Orang Tua dengan Perkembangan Kognitif Anak.

Harapan Untuk menambah wawasan dan pengetahuan orang tua dalam mengenal dasar-dasar pola asuh orang tua dengan perkembangan kognitif anak.

\section{Referensi}

Cristiana. (2014). Perkembangan Anak Sejak Perubahan Sampai Kanak-Kanak Akhir. Jakarta: Prenadamedia Group.

Kusuma, F. A., \& Wadi, H. (2015). 1, 2 , 3 ., 2(2), 9043.

Mutiara, D. (2015). Psikologi Bermain Anak Usia Dini. Jakarta: Prenadamedia Group.

Shantika. (2017). Golden Age Pareting (memaksimalkan potensi anak di usia emas. Yogyakarta: Psikologi Corner.

Supardi, R. \&. (n.d.). Metodologi Risset Penelitian 1. Jakarta: CV Trans Info Media.

Susanto. (2014). Perkembangan Usia Dini Pengantar dalam Berbagai Aspeknya. Jakarta: Prenadamedia Group.

Tridhonanto. (2014). Mengembangkan Pola Asuh Demokratis. Jakarta: Salemba medika. 